\title{
Successful Treatment of Richter Transformation with Ibrutinib in a Patient with Chronic Lymphocytic Leukemia following Allogeneic Hematopoietic Stem Cell Transplant
}

\author{
Samip Master Cheri Leary Amol Takalkar James Coltelingam \\ Richard Mansour Glenn M. Mills Nebu Koshy \\ Louisiana State University Health Sciences Center, Shreveport, LA, USA
}

\section{Keywords}

Ibrutinib · Richter transformation - Chronic lymphocytic leukemia - Ibrutinib after allogeneic transplant

\begin{abstract}
Patients with chronic lymphocytic leukemia (CLL) who progress to Richter transformation (RT) have a poor prognosis. Multi-agent chemotherapy regimens do not have good response rates. There are few case reports on the use of ibrutinib in RT. Here, we present a patient who was heavily pretreated for $\mathrm{CLL}$, including allogeneic stem cell transplant, and progressed to RT. She had a mixed response to multi-agent chemotherapy and was started on ibrutinib. She had a complete response for 16 months on single-agent ibrutinib with minimal toxicity.

(C) 2017 The Author(s)

Published by S. Karger AG, Basel
\end{abstract}




\section{Case Reports in Oncology} \begin{tabular}{l|l}
\hline Case Rep Oncol 2017;10:534-541 \\
\hline DOI: 10.1159/000477338 & $\begin{array}{l}\text { (C) 2017 The Author(s). Published by S. Karger AG, Basel } \\
\text { www.karger.com/cro }\end{array}$
\end{tabular}

Master et al.: Successful Treatment of RT with Ibrutinib in a Patient with CLL following Allogeneic Hematopoietic Stem Cell Transplant

\section{Introduction}

Richter transformation (RT) is defined as the transformation of chronic lymphocytic leukemia (CLL) into a more aggressive lymphoma. Diffuse large B-cell lymphoma (DLBCL) is the most common histology seen in patients with RT [1]. Other histologies, such as Hodgkin lymphoma [2,3] and T-cell lymphomas [4], are less common. Approximately 2-9\% of patients with CLL progress to RT [1,5-8]. The transformation rate is $0.5-1 \%$ per year [9]. The median time from the diagnosis to RT ranges from 2 to 4 years $[5,7,10]$. RT is a rapidly progressive disease with a median survival of months $[1,5,11]$. Here, we report a case of successful treatment of RT with ibrutinib following allogeneic hematopoietic stem cell transplant (HSCT) for CLL.

\section{Case Report}

A 47-year-old female with relapsed refractory CLL, which was initially diagnosed in 2003, was treated with multiple lines of therapy, including the combination fludarabine, cyclophosphamide, rituximab (FCR), and later with alemtuzumab. The patient developed $17 p$ deletion in 2012 and underwent matched related allogeneic HSCT in November 2013. She had no evidence of disease recurrence until April 2015, when she had worsening cytopenia and a bone marrow biopsy was consistent with RT (Fig. 1). A PET scan (Fig. 2a) revealed extensive lymphadenopathy in the pelvis and abdomen. She was treated with combination chemotherapy with rituximab-ifosfamide/carboplatin/etoposide (R-ICE). She had a poor response after 3 cycles of R-ICE (Fig. 2b). Ibrutinib $420 \mathrm{mg}$ daily was started in July 2015, and a repeat PET scan in November 2015 (Fig. 2c) revealed excellent metabolic response with virtual complete interval resolution of the previously noted extensive FDG avid lymphadenopathy. A repeat bone marrow biopsy revealed minimal residual CLL with no evidence of RT (Fig. 3) and improvement of cytopenia. Around 16 months after starting ibrutinib, she was noted to have worsening cytopenia again and a repeat bone marrow biopsy confirmed the recurrence of RT. Hospice care versus further treatment with venetoclax was discussed. The patient continued to progress on venetoclax and opted for hospice care.

\section{Discussion}

RT has been associated with a dismal prognosis. In the largest reported series of 148 patients with biopsy-proven RT, the overall response rate to a variety of regimens was $39 \%$, with $12 \%$ complete responses [12]. The following are poor prognostic factors for RT based on the previously mentioned study and another series of 86 patients [13].

- Platelet count $<100,000 / \mu \mathrm{L}$

- ECOG (Zubrod) performance status $>1$

- Tumor size $>5 \mathrm{~cm}$

- $>1$ prior treatment

- Lactate dehydrogenase level >1.5 times the upper limit of normal 


\section{Case Reports in Oncology}

Master et al.: Successful Treatment of RT with Ibrutinib in a Patient with CLL following Allogeneic Hematopoietic Stem Cell Transplant

- Failure to achieve a complete remission after induction therapy for RT

- TP53 disruption on molecular analysis.

Our patient had a poor prognosis based on the abovementioned factors, namely thrombocytopenia, 17p deletion, lactate dehydrogenase elevation, ECOG 2, more than 1 prior treatment, and failure to achieve complete remission after induction. Based on the abovementioned studies, the expected survival for our patient ranged from 3.6 to 7.8 months.

Treatment of RT generally relies on combination chemotherapy such as that used for aggressive non-Hodgkin lymphomas or acute lymphoblastic leukemia, with overall response rates ranging from 5 to $40 \%$ [1, 14-16]. Given the poor efficacy of combination chemotherapy, the short duration of remission, and the poor overall survival (OS) of patients with RT, autologous and allogeneic HSCT have been explored as a therapeutic option. Data are limited to retrospective case series $[12,17,18]$. Together, these studies suggest a benefit from the use of autologous or allogeneic HSCT in those patients with chemosensitive disease. A choice among these management options must take into consideration the patient age and comorbidities, as well as the disease status. Autologous HSCT may be preferred for older adults and/or those with chemosensitive disease.

A retrospective analysis was done on 72 patients ( 52 with CLL and 20 with RT) who underwent allogeneic stem cell transplant. The 2- and 5-year survival rates were 67 and 38\% in patients with CLL and 36 and $0 \%$ in patients with RT, respectively. The patients who developed acute or chronic graft-versus-host disease had a longer OS $(p=0.05)$. In a multivariable analysis, RT or low hemoglobin at the time of stem cell transplant predicted a shorter OS. Chronic graft-versus-host disease and an initial response to stem cell transplant predicted a longer OS [25]. These results demonstrate the continued need for additional effective therapeutic agents in the setting of postallogeneic transplant relapse.

Ibrutinib is a potent and irreversible inhibitor of Bruton's tyrosine kinase and interleukin-2-inducible kinase (ITK). It has been used to treat relapsed/refractory CLL with high response rates as well as prolonged progression-free survival and OS [19-24]. In 1 study of 132 CLL patients with either treatment-naïve or relapsed/refractory CLL, the most common responses to single-agent ibrutinib were durable partial responses, with an $83 \%$ OS rate at 30 months of follow-up [25].

Ryan et al. [26] demonstrated that ibrutinib had response rates of $87.5 \%$ in a series of 27 patients who relapsed after allogeneic transplant in CLL. The authors postulated that ITK inhibition by ibrutinib augments the graft-versus-leukemia effect. However, none of these patients developed graft-versus-host disease. Comprehensive immune phenotype characterization of peripheral $\mathrm{B}$ and $\mathrm{T}$ cells showed that ibrutinib selectively targets pregerminal B cells and depletes Th2 helper cells [26]. ITK plays a key role in the activation of both Th1 and Th2 cells. Other smaller studies have also demonstrated promising results in using salvage ibrutinib after relapse following allogeneic transplant in CLL patients $[27,28]$.

As shown in Table 1, there are case reports that show efficacy of ibrutinib in RT. In a case series of 4 patients with RT, who were treated with salvage ibrutinib, the median duration of ibrutinib treatment was 6.1 months (range, 2.8-10.8 months). All patients experienced an improvement in constitutional symptoms. One patient had a complete response and 2 patients had a partial response. The fourth patient was started on low-dose ibrutinib 


\section{Case Reports in Oncology}

(140 mg per day) because of concomitant voriconazole use (metabolized through the CYP3A4 pathway); he subsequently died of pulmonary mucormycosis (diagnosed prior to ibrutinib initiation) after 15 weeks of therapy and prior to repeat imaging to allow for response assessment. Ibrutinib was well tolerated; no patient required discontinuation as a result of adverse events [29]. Two other reports of ibrutinib use in RT were published by Giri et al. [30]: one of the patients with no significant gene mutation responded well to ibrutinib.

As previously mentioned, the most common pathology of RT is DLBCL. Ibrutinib has shown good responses in subjects with DLBCL as a single agent in a relapsed/refractory setting [31] and also as part of rituximab, cyclophosphamide, doxorubicin, vincristine, and prednisone (R-CHOP) [32]. BCL 2 antagonist, NOTCH 1 inhibitors, and idelalisib are some other approaches that hold some promise for RT [9]. Unfortunately, our patient progressed after 16 months of ibrutinib and venetoclax was tried, but she progressed and opted for hospice.

\section{Conclusion}

Based on the above discussion, we conclude that newer modalities are needed for the management of RT, which has a dismal prognosis. Ibrutinib has shown response in RT and in DLBCL, which is the most common histology of RT. Ibrutinib has been used in relapse of CLL after allogeneic transplant with good tolerability. Our patient progressed to RT and had a complete response for 16 months on single-agent ibrutinib. Our case shows the possible role of ibrutinib in the treatment of RT and as maintenance therapy after allogeneic transplant in patients with CLL.

\section{Statement of Ethics}

The authors have no conflicts of interest to disclose

\section{Disclosure Statement}

The authors have no conflict of interest to disclose.

\section{References}

1 Tsimberidou AM, Keating MJ: Richter syndrome: biology, incidence, and therapeutic strategies. Cancer 2005;103:216-228.

-2 Brecher M, Banks PM: Hodgkin's disease variant of Richter's syndrome. Report of eight cases. Am J Clin Pathol 1990;93:333-339.

-3 Bockorny B, Codreanu I, Dasanu CA: Hodgkin lymphoma as Richter transformation in chronic lymphocytic leukaemia: a retrospective analysis of world literature. Br J Haematol 2012;156:50-66. 
4 Lee A, et al: B-cell chronic lymphocytic leukemia followed by high grade T-cell lymphoma. An unusual variant of Richter's syndrome. Am J Clin Pathol 1995;103:348-352.

Robertson LE, et al: Richter's syndrome: a report on 39 patients. J Clin Oncol 1993;11:1985-1989. Yee KW, O’Brien SM, Giles FJ: Richter's syndrome: biology and therapy. Cancer J 2005;11:161-174. Rossi D, et al: Biological and clinical risk factors of chronic lymphocytic leukaemia transformation to Richter syndrome. Br J Haematol 2008;142:202-215. Parikh SA, et al: Diffuse large B-cell lymphoma (Richter syndrome) in patients with chronic lymphocytic leukaemia (CLL): a cohort study of newly diagnosed patients. Br J Haematol 2013;162:774-782. Parikh SA, Kay NE, Shanafelt TD: How we treat Richter syndrome. Blood 2014;123:1647-1657. Harousseau JL, et al: Malignant lymphoma supervening in chronic lymphocytic leukemia and related disorders. Richter's syndrome: a study of 25 cases. Cancer 1981;48:1302-1308. Tsimberidou AM, et al: Phase II study of fludarabine, cytarabine (Ara-C), cyclophosphamide, cisplatin and GM-CSF (FACPGM) in patients with Richter's syndrome or refractory lymphoproliferative disorders. Leuk Lymphoma 2002;43:767-772. Tsimberidou AM, et al: Clinical outcomes and prognostic factors in patients with Richter's syndrome treated with chemotherapy or chemoimmunotherapy with or without stem-cell transplantation. J Clin Oncol 2006;24:2343-2351.

Rossi D, et al: The genetics of Richter syndrome reveals disease heterogeneity and predicts survival after transformation. Blood 2011;117:3391-3401. Dabaja BS, et al: Fractionated cyclophosphamide, vincristine, liposomal daunorubicin (daunoXome), and dexamethasone (hyperCVXD) regimen in Richter's syndrome. Leuk Lymphoma 2001;42:329-337. Tsimberidou AM, et al: Fractionated cyclophosphamide, vincristine, liposomal daunorubicin, and dexamethasone plus rituximab and granulocyte-macrophage-colony stimulating factor (GM-CSF) alternating with methotrexate and cytarabine plus rituximab and GM-CSF in patients with Richter syndrome or fludarabine-refractory chronic lymphocytic leukemia. Cancer 2003;97:1711-1720. Tsimberidou AM, et al: Yttrium-90 ibritumomab tiuxetan radioimmunotherapy in Richter syndrome. Cancer 2004;100:2195-2200. Rodriguez J, et al: Allogeneic haematopoietic transplantation for Richter's syndrome. Br J Haematol 2000;110:897-899.

18 Cwynarski K, et al: Autologous and allogeneic stem-cell transplantation for transformed chronic lymphocytic leukemia (Richter's syndrome): a retrospective analysis from the Chronic Lymphocytic Leukemia Subcommittee of the Chronic Leukemia Working Party and Lymphoma Working Party of the European Group for Blood and Marrow Transplantation. J Clin Oncol 2012;30:2211-2217. Honigberg LA, et al: The Bruton tyrosine kinase inhibitor PCI-32765 blocks B-cell activation and is efficacious in models of autoimmune disease and B-cell malignancy. Proc Natl Acad Sci USA 2010;107:13075-13080.

-20 Herman SE, et al: Bruton tyrosine kinase represents a promising therapeutic target for treatment of chronic lymphocytic leukemia and is effectively targeted by PCI-32765. Blood 2011;117:6287-6296. Byrd JC, et al: Targeting BTK with ibrutinib in relapsed chronic lymphocytic leukemia. N Engl J Med 2013;369:32-42. O'Brien S, et al: Ibrutinib as initial therapy for elderly patients with chronic lymphocytic leukaemia or small lymphocytic lymphoma: an open-label, multicentre, phase 1b/2 trial. Lancet Oncol 2014;15:4858.

Burger JA, et al: Safety and activity of ibrutinib plus rituximab for patients with high-risk chronic lymphocytic leukaemia: a single-arm, phase 2 study. Lancet Oncol 2014;15:1090-1099. Byrd JC, et al: Ibrutinib versus ofatumumab in previously treated chronic lymphoid leukemia. N Engl J Med 2014;371:213-223.

25 Byrd JC, et al: Three-year follow-up of treatment-naive and previously treated patients with CLL and SLL receiving single-agent ibrutinib. Blood 2015;125:2497-2506.

-26 Ryan CE, et al: Ibrutinib efficacy and tolerability in patients with relapsed chronic lymphocytic leukemia following allogeneic HCT. Blood 2016;128:2899-2908.

27 Rozovski U, et al: Outcomes of patients with chronic lymphocytic leukemia and Richter's transformation after transplantation failure. J Clin Oncol 2015;33:1557-1563.

-28 Link CS, et al: Durable responses to ibrutinib in patients with relapsed CLL after allogeneic stem cell transplantation. Bone Marrow Transplant 2016;51:793-798.

-29 Tsang M, et al: The efficacy of ibrutinib in the treatment of Richter syndrome. Blood 2015;125:16761678.

- 30 Giri S, et al: Ibrutinib has some activity in Richter's syndrome. Blood Cancer J 2015;5:e277. 


\section{Case Reports in Oncology}

\begin{tabular}{l|l}
\hline Case Rep Oncol 2017;10:534-541 \\
\hline DOI: 10.1159/000477338 & $\begin{array}{l}\text { ( } 2017 \text { The Author(s). Published by S. Karger AG, Basel } \\
\text { www.karger.com/cro }\end{array}$
\end{tabular}

Master et al.: Successful Treatment of RT with Ibrutinib in a Patient with CLL following Allogeneic Hematopoietic Stem Cell Transplant

-31 Wilson WH, et al: Targeting B cell receptor signaling with ibrutinib in diffuse large B cell lymphoma. Nat Med 2015;21:922-926.

32 Younes A, et al: Combination of ibrutinib with rituximab, cyclophosphamide, doxorubicin, vincristine, and prednisone (R-CHOP) for treatment-naive patients with CD20-positive B-cell non-Hodgkin lymphoma: a non-randomised, phase 1b study. Lancet Oncol 2014;15:1019-1026.

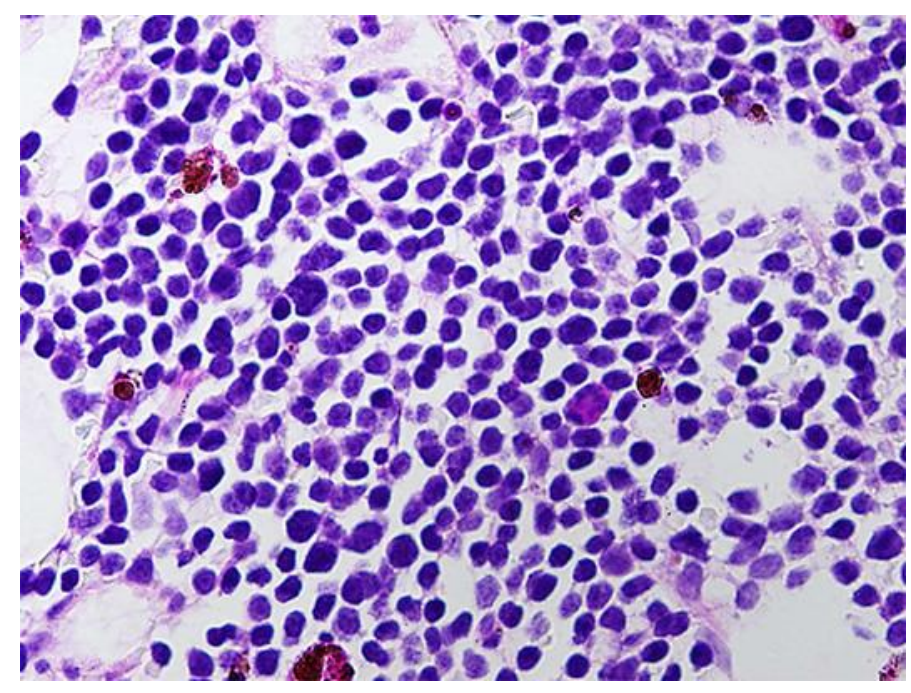

Fig. 1. Bone marrow biopsy showing RT. 


\section{Case Reports in Oncology}

\begin{tabular}{l|l}
\hline Case Rep Oncol 2017;10:534-541 \\
\hline DOI: 10.1159/000477338 & $\begin{array}{l}\text { (c) 2017 The Author(s). Published by S. Karger AG, Basel } \\
\text { www.karger.com/cro }\end{array}$
\end{tabular}

Master et al.: Successful Treatment of RT with Ibrutinib in a Patient with CLL following Allogeneic Hematopoietic Stem Cell Transplant
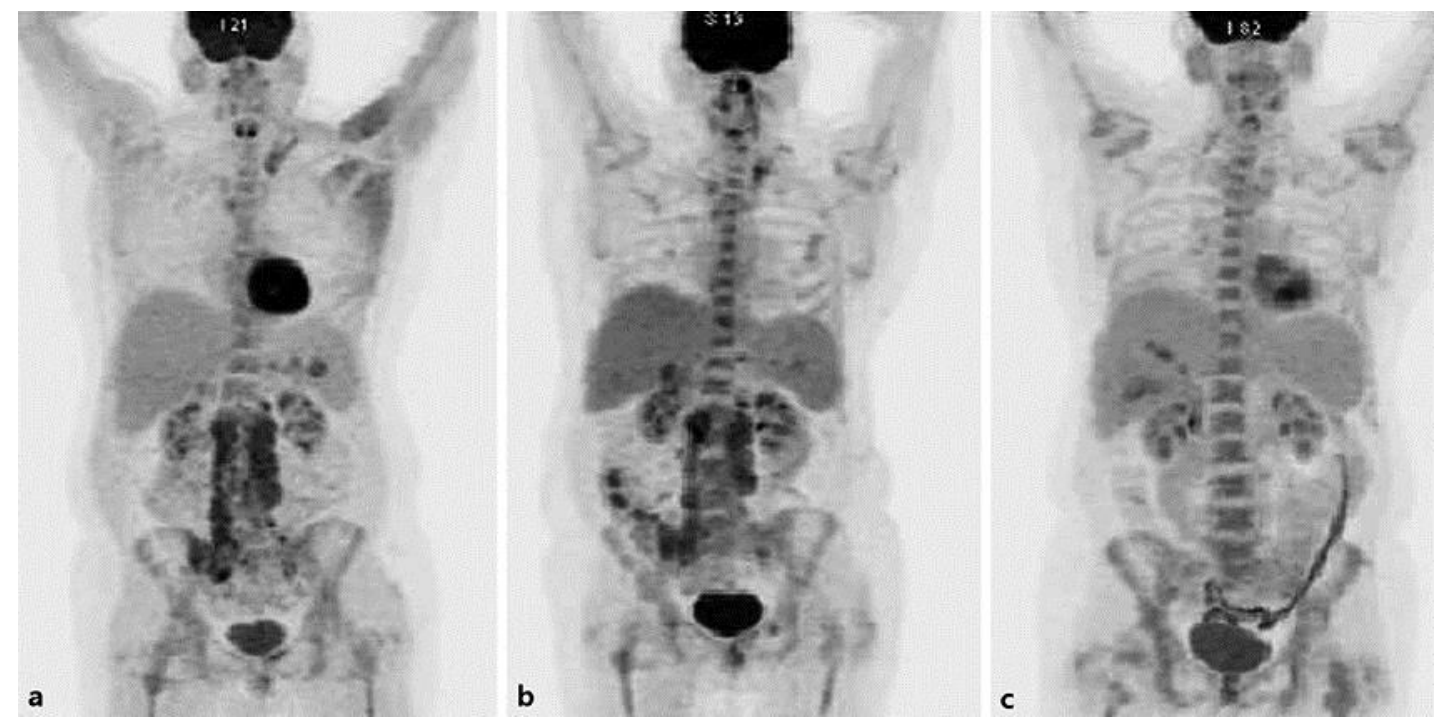

Fig. 2. a PET scan showing extensive lymphadenopathy in the pelvis and abdomen consistent with the diagnosis of RT. b PET scan after 3 cycles of combination chemotherapy with rituximab-ifosfamide/ carboplatin/etoposide (R-ICE). c PET scan showing excellent metabolic response with virtual complete interval resolution of the previously noted extensive FDG avid lymphadenopathy with ibrutinib therapy.

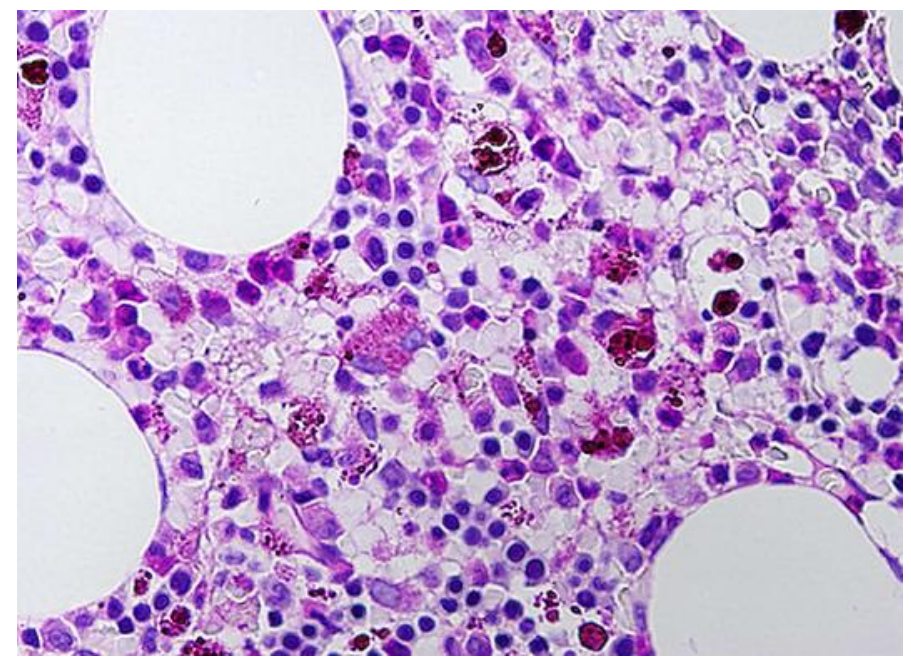

Fig. 3. Bone marrow biopsy showing minimal residual CLL with no evidence of RT. 


\section{Case Reports in Oncology}

Table 1. Published case reports of use of ibrutinib in RT

\begin{tabular}{|c|c|c|c|c|c|c|c|}
\hline & \multicolumn{7}{|l|}{ Patient [Ref.] } \\
\hline & $1[29]$ & 2 [29] & 3 [29] & 4 [29] & 5 [30] & $6[30]$ & This case report \\
\hline $\begin{array}{l}\text { Age at CLL } \\
\text { diagnosis, } \\
\text { years }\end{array}$ & 51 & 69 & 65 & 71 & 60 & 59 & 35 \\
\hline Gender & $\mathrm{F}$ & $\mathrm{M}$ & $\mathrm{M}$ & $\mathrm{F}$ & $\mathrm{M}$ & $\mathrm{M}$ & $\mathrm{F}$ \\
\hline FISH & Del $13 \mathrm{q}$ & & & Del 17p & & $\begin{array}{l}\text { Trisomy } 12 \\
\text { and P52 del }\end{array}$ & Del 17p \\
\hline $\begin{array}{l}\text { CLL } \\
\text { therapy }\end{array}$ & $\begin{array}{l}\text { 1. R A } \\
\text { 2. P C R } \\
\text { 3. E A }\end{array}$ & B R & PCR & $\begin{array}{l}\text { 1. B R } \\
\text { 2. E A } \\
\text { 3. } 0 \\
\text { 4. A }\end{array}$ & & $\begin{array}{l}\text { 1. B R } \\
\text { 2.FCR }\end{array}$ & $\begin{array}{l}\text { 1. R } \\
\text { 2. F C R } \\
\text { 3. F C R + } \\
\text { lumiliximab × } 5 \\
\text { 4. A } \\
\text { 5. allogenic SCT }\end{array}$ \\
\hline $\begin{array}{l}\text { Age at RT, } \\
\text { years }\end{array}$ & 62 & 74 & 68 & 74 & 60 & 67 & 46 \\
\hline $\begin{array}{l}\text { Initial } \\
\text { therapy } \\
\text { for RT }\end{array}$ & $\begin{array}{l}\text { 1. R-CHOP } \\
\text { (2 cycles, PR) } \\
\text { 2. R-ICE } \\
\text { (1 cycle, PD) } \\
\text { 3. Palliative therapy } \\
\text { with steroids (6 } \\
\text { weeks, SD) }\end{array}$ & $\begin{array}{l}\text { 1. R-CHOP } \\
\text { ( } 2 \text { cycles, PD) } \\
\text { 2. R-EPOCH } \\
(2 \text { cycles, PD) }\end{array}$ & $\begin{array}{l}\text { 1. R-CHOP } \\
\text { ( } 2 \text { cycles, PD) } \\
\text { 2. R-ICE } \\
\text { ( } 3 \text { cycles, PD) } \\
\text { 3. R DHAP } \\
\text { ( } 2 \text { cycles , PD) }\end{array}$ & None & $\begin{array}{l}\text { 1. R-CHOP } \\
\text { 2. R-ICE } \\
\text { 3. R Gem Onc } \\
\text { (refractory to } \\
\text { all 3) }\end{array}$ & $\begin{array}{l}\text { 1. R-CHOP } \\
\text { 2. R-ICE }\end{array}$ & $\begin{array}{l}\text { R-ICE, mixed } \\
\text { response }\end{array}$ \\
\hline $\begin{array}{l}\text { Ibrutinib } \\
\text { dose, mg }\end{array}$ & 420 & 140 & 420 & 420 & & & $420 \rightarrow 280$ \\
\hline $\begin{array}{l}\text { Duration } \\
\text { of therapy, } \\
\text { months }\end{array}$ & 8.5 & 3.7 & 2.8 & 10.8 & & 2 & 16 \\
\hline $\begin{array}{l}\text { Best } \\
\text { response }\end{array}$ & PR & $\begin{array}{l}\text { Clinical } \\
\text { benefit }\end{array}$ & $\mathrm{CR}$ & PR & $\begin{array}{l}90 \% \text { regression } \\
\text { in } 3 \text { months }\end{array}$ & PD & $\mathrm{CR}$ \\
\hline
\end{tabular}

R, rituximab; C, cyclophosphamide; B, bendamustine; A, alemtuzumab; P, pentostatin; E, everolimus; O, ofatumumab; F, fludarabine; R-CHOP, rituximab, cyclophosphamide, doxorubicin, vincristine, and prednisone; R-ICE, rituximab, ifosamide, carboplatin, and etoposide; R-EPOCH, rituximab, etoposide, prednisone, vincristine, cyclophosphamide, and doxorubicin; Gem, gemcitabine; PD, progressive disease; CR, complete response; PR, partial response; SD, stable disease; SCT, stem cell transplant. 